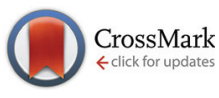

Cite this: Org. Biomol. Chem., 2016, 14,5606

Received 15th February 2016,

Accepted 6th April 2016

DOI: $10.1039 / c 6 o b 00365 f$

www.rsc.org/obc

\section{Protein-specific localization of a rhodamine-based calcium-sensor in living cells $\uparrow$}

\author{
Marcel Best, ${ }^{a}$ Isabel Porth, ${ }^{a}$ Sebastian Hauke, ${ }^{b}$ Felix Braun, ${ }^{c}$ Dirk-Peter Herten ${ }^{c}$ and \\ Richard Wombacher*a
}

\begin{abstract}
A small synthetic calcium sensor that can be site-specifically coupled to proteins in living cells by utilizing the bio-orthogonal HaloTag labeling strategy is presented. We synthesized an iododerivatized BAPTA chelator with a tetramethyl rhodamine fluorophore that allows further modification by Sonogashira cross-coupling. The presented calcium sensitive dye shows a 200-fold increase in fluorescence upon calcium binding. The derivatization with an aliphatic linker bearing a terminal haloalkane-function by Sonogashira cross-coupling allows the localization of the calcium sensor to Halo fusion proteins which we successfully demonstrate in in vitro and in vivo experiments. The herein reported highly sensitive tetramethyl rhodamine based calcium indicator, which can be selectively localized to proteins, is a powerful tool to determine changes in calcium levels inside living cells with spatiotemporal resolution.
\end{abstract}

\section{Introduction}

Calcium plays a key role as second messenger in living cells and both the spatial and temporal changes of its endogenous concentration $\left[\mathrm{Ca}^{2+}\right]_{\mathrm{i}}$ have a significant effect on signaling transduction in excitable and non-excitable cells. ${ }^{1}$ Different approaches to measure calcium fluctuations in live cell experiments have been developed: the genetically encoded calcium indicators (GECIs) ${ }^{2}$ utilize calcium sensitive fluorescent proteins or fusion proteins with the so-called "cameleons" ${ }^{3}$ and "camgaroos" 4 as well known examples. GECIs have the advantage that they can be genetically targeted to any protein of

\footnotetext{
${ }^{a}$ Ruprecht-Karls-University Heidelberg, Institute for Pharmacy und Molecular Biotechnology, Im Neuenheimer Feld 364, 69120 Heidelberg, Germany. E-mail: wombacher@uni-heidelberg.de; Fax:+49(0)621 544879; Tel: +49 (0)621 544879

${ }^{b}$ European Molecular Biology Laboratory, Cell Biology and Biophysics Unit, Meyerhofstraße 1, 69117 Heidelberg, Germany

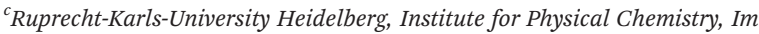
Neuenheimer Feld 267, 69120 Heidelberg, Germany

$\dagger$ Electronic supplementary information (ESI) available. See DOI: 10.1039/ c6ob00365f
}

interest (POI), but they lack fast response to quick changes of $\left[\mathrm{Ca}^{2+}\right]_{\mathrm{i}}$ in living cells. ${ }^{5}$ Alternatively, small synthetic calcium indicators ${ }^{6}$ as Indo-1/Fura $1-3,{ }^{7}$ Rhod- $1+2 /$ Fluo1 $^{-} 3^{8}$ and Fluo$4^{9}$ have been developed for calcium imaging in live cells and organisms with the advantage of being much smaller in size compared to fluorescent proteins and therefore less disruptive. Furthermore they can be chemically modified to adapt both the chemical and physical properties to the experimental needs. Over the last decades, numerous small synthetic calcium sensors have been developed and used for calcium measurements in living systems. ${ }^{10}$ However, their application is limited to the measurements of $\left[\mathrm{Ca}^{2+}\right]_{\mathrm{i}}$ in the cytosolic environment as they lack the ability to be specifically localized within the cells. Recently, protein labeling strategies for sitespecific localization of small synthetic calcium sensors to a POI utilizing the FlAsH ${ }^{5}$ and SNAP-tag protein ${ }^{11}$ labeling strategy have been reported. Whereas the calcium sensor for FlAsH-tag applications is based on fluorescein combined with the calcium binding APTRA (2-aminophenol- $N, N, O$-tri-acetat) ${ }^{12}$ motive, the SNAP-tag based approach utilizes a BODIPY (boron dipyrromethene $)^{13}$ conjugated to the well-known BAPTA (1,2 bis-(ortho-aminophenoxy)ethane- $N, N, N^{\prime}, N^{\prime}$-tetra-acetate $)^{14}$ calcium-ion chelator. The fluorophores used in these studies need to be excited in the blue range of the spectrum, whereas calcium indicators for protein localization, which can be excited at longer wavelengths, have not been reported yet. Here we introduce a new sensitive synthetic calcium indicator based on the fluorophore rhodamine that can be specifically localized to a POI in living cells utilizing the Halo-tag protein labeling strategy (Fig. 1). ${ }^{15}$ The new calcium sensor shows a $>200$ fold increase in fluorescence upon calcium binding and can be excited in the green spectrum $\left(\mathrm{Ex}_{\max }=552 \mathrm{~nm} ; \mathrm{Em}_{\max }=\right.$ $580 \mathrm{~nm}$ ). In a first proof of principle, we demonstrate the specific localization of the calcium sensitive fluorophore to a POI by labeling of a purified Halo fusion protein. For live cell application of the presented strategy, we performed specific labeling of nucleus localized Halo tagged histone protein (H2B) with the calcium sensor. We show that the H2B localized calcium sensor can be used to monitor nuclear calcium 
A
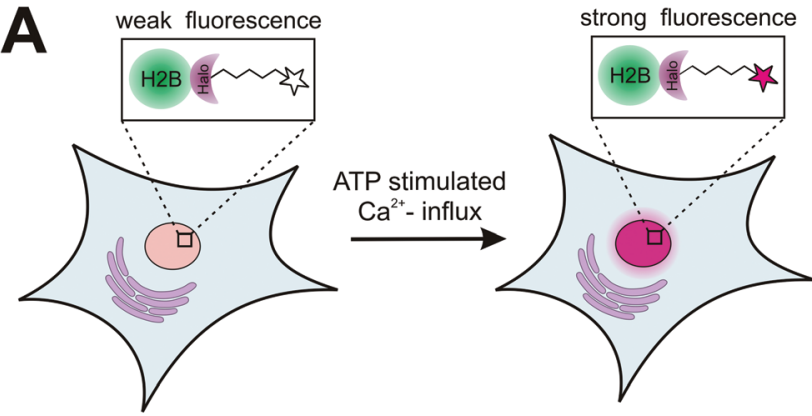

B

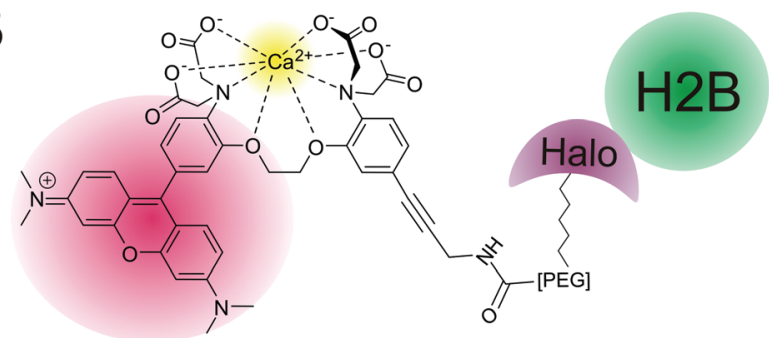

Fig. 1 (A) Measurement of spatiotemporal changes of calcium levels (e.g. in the nucleus) using the RhoCa-Halo probe. Halo-H2B fusion protein, transiently expressed in cells can be specifically labeled with the calcium sensitive probe RhoCa-Halo. ATP stimulated influx of free calcium ions into the cytosol can be visualized by a significant fluorescence increase of the localized probe. (B) Structure of the rhodamine based RhoCa-Halo. The calcium sensor was derivatized at the calcium sensitive BAPTA-site by Sonogashira cross-coupling to introduce a haloalkane function for site-specific labeling by utilizing the HaloTagstrategy. changes in living cells. The herein presented localizable rhodamine derived calcium indicator can be used to measure rapid spatiotemporal changes of $\left[\mathrm{Ca}^{2+}\right]_{\mathrm{i}}$ in living cells.

\section{Results and discussion}

The considerations for the development of the calcium sensor were based on the high photostability and brightness of the fluorophore tetramethyl rhodamine (TAMRA) in aqueous systems ${ }^{16}$ and the high selectivity of the BAPTA chelator in the presence of magnesium ions. ${ }^{14}$ The commercially available Rhod-2 calcium indicator ${ }^{8}$ which is based on these both chemical components has a $K_{\mathrm{d}}$-value in the nanomolar range and became a standard tool for calcium measurements in living cells. ${ }^{8,17}$ However, the mitochondrial localization ${ }^{18}$ of rhodamine derivatives limits its application. Therefore we sought to develop a calcium indicator with the advantageous photophysical properties of a rhodamine, the excellent calcium selectivity and sensitivity of BAPTA and an additional functionality for further chemical modification. The additional functionality will then be used to attach a haloalkane which serves as a substrate for the HaloTag and enables the covalent attachment to Halo fusion proteins. The highly selective protein localization will then suppress the unwanted mitochondrial localization of the rhodamines. For this reason, we first synthesized a BAPTA core with an iodine modification that allows the selective functionalization by Sonogashira cross-coupling in a final step. Scheme 1 outlines the synthesis<smiles>O=[N+]([O-])c1ccccc1OCCBr</smiles><smiles>O=[N+]([O-])c1ccccc1OCCOc1cc(I)ccc1[N+](=O)[O-]</smiles><smiles>[GeH3]</smiles><smiles>Nc1ccccc1OCCOc1cc(I)ccc1N</smiles><smiles>COC(=O)CN(CC(=O)OC)c1ccccc1OCCOc1cc(I)ccc1N(CC(=O)OC)CC(=O)OC</smiles><smiles>COC(=O)CN(CC(=O)OC)c1ccc(C)cc1OCCOc1cc(C=O)ccc1N(CC(=O)OC)CC(=O)OC</smiles><smiles>COC(=O)CN(CC(=O)OC)c1ccc(I)cc1OCCOc1cc(-c2c3ccc(=[N+](C)C)cc-3oc3cc(N(C)C)ccc23)ccc1N(CC(=O)OC)CC(=O)OC</smiles><smiles>[R]OC(=O)OCc1ccc(-c2c3ccc(=[N+](C)C)cc-3oc3cc(N(C)C)ccc23)c(N(CC(=O)O)CC(=O)O)c1</smiles><smiles>[18OH]</smiles><smiles>CC(=O)CN(CCOC(C)=O)c1ccc(I)cc1OCCOc1cc(-c2c3ccc(=[N+](C)C)cc-3oc3cc(N(C)C)ccc23)ccc1N(CC(C)=O)CC(C)=O</smiles>

Scheme 1 Synthesis of RhoCa-I and RhoCa-I AM. Reaction conditions: (a) $\mathrm{K}_{2} \mathrm{CO}_{3}, 1$,2-dibromoethane, MeCN, reflux; 85\%; (b) 5-iodo-2-nitrophenol, $\mathrm{K}_{2} \mathrm{CO}_{3}, \mathrm{DMF}, 45^{\circ} \mathrm{C}$; (c) $1, \mathrm{DMF}, 130{ }^{\circ} \mathrm{Co} / \mathrm{n}, 84 \%$; (d) $\mathrm{Sn} / \mathrm{HCl}$, reflux, quant.; (e) methyl bromoacetate, Nal, proton sponge, MeCN, reflux, $28 \%$; (f) DMF, $\mathrm{POCl}_{3}$, pyridine, $80{ }^{\circ} \mathrm{C}$; (g) $\mathrm{H}_{2} \mathrm{O}, 0{ }^{\circ} \mathrm{C}, 27 \%$; (h) 3-(dimethylamino)-phenol, propionic acid, $110{ }^{\circ} \mathrm{C}$; (i) $p$-chloranil, $\mathrm{DCM} / \mathrm{MeOH}$, rt, $14 \%$; (j) $\mathrm{DCM} / \mathrm{MeOH}, 1 \mathrm{M} \mathrm{NaOH}, \mathrm{rt}, 67 \%$; (k) bromomethyl acetate, (iPr) $2 \mathrm{NEt}, \mathrm{DCM}, \mathrm{rt}, 13 \%$. 
of RhoCa-I, the iodine modified BAPTA calcium chelator coupled to rhodamine. First ortho-nitrophenol was alkylated with 1,2-dibromoethane under basic conditions to yield $\mathbf{1}$. Further alkylation with 5-iodo-2-nitrophenol and reduction of the nitro functions resulted in the diamine 3. Alkylation with methyl bromoacetate followed by Vilsmeier-Haack formylation yielded 5 which was then converted to the BAPTA rhodamine 6 by treatment of $\mathbf{5}$ with 3-(dimethylamino)-phenol under acetic conditions and subsequent oxidation. ${ }^{19}$ Finally, the methyl esters of 6 were saponified to obtain the calcium sensitive RhoCa-I. To render the newly synthesized calcium indicator cell permeable for its application in living cells, 6 was converted to the respective acetoxymethyl ester (AM-ester) RhoCa-I AM.

Calcium titration (in an EGTA-buffered solution with free calcium concentrations ranging from $0 \mu \mathrm{M}$ to $39 \mu \mathrm{M}$, Fig. S1A, $\uparrow \lambda_{\text {ex }}=552 \mathrm{~nm}$ ) of RhoCa-I revealed a 215 -fold fluorescence enhancement upon calcium binding and a $K_{\mathrm{d}}$-value of $2.50 \pm 0.17 \mu \mathrm{M}$ (Fig. $\mathrm{S} 1 \mathrm{~B} \dagger$ ). The relative quantum yield ${ }^{20}$ was determined to be $20.9 \pm 0.6 \%$ at $\left[\mathrm{Ca}^{2+}\right]_{\text {free }}=39 \mu \mathrm{M}$ and $0.07 \pm$ $0.01 \%$ at $\left[\mathrm{Ca}^{2+}\right]_{\text {free }}=0 \mu \mathrm{M}$ in reference to Rhodamine $\mathrm{B} .{ }^{21}$ As expected, the $K_{\mathrm{d}}$-value of $2.5 \mu \mathrm{M}$ is significantly higher than the $K_{\mathrm{d}}$-value of Rhod-2 $(\sim 570 \mathrm{nM}),{ }^{10}$ which has a methyl group in para-position to the alkyl amine groups. We assume that that the higher $K_{\mathrm{d}}$-value is due to the iodine substituent as electron withdrawing groups are known to decrease the calcium affinity of the BAPTA chelator. ${ }^{22}$

Next, we evaluated the calcium sensitivity of RhoCa-I in living cells. Therefore, HeLa cells were incubated with the AM ester of the photo-cleavable $o$-nitrophenyl EGTA (NP-EGTA $^{23}$ $\mathrm{AM})$ which has a high affinity for calcium ions $\left(K_{\mathrm{d}}=80 \mathrm{nM}\right)$. One of the chelating moieties can be cleaved off by UV-light radiation, thereby lowering the $\mathrm{Ca}^{2+}$ affinity by a factor of more than 10000 . To release calcium ions from cellular internal stores, the HeLa cells were stimulated with $100 \mu \mathrm{M} \mathrm{ATP}^{24}$ followed by the incubation with $10 \mu \mathrm{M}$ of the $\mathrm{AM}$ ester $^{25}$ of Rho-Ca-I (RhoCa-I AM). As presented in Fig. 2, the calcium sensor shows a significant increase of fluorescence intensity after calcium release from NP-EGTA after UV-radiation. As mentioned before, rhodamine dyes tend to localize to mitochondria what we also observed for the calcium sensor RhoCa-I (Fig. 2A). To overcome that limitation and to actively choose the subcellular site for localization, we further synthesized the calcium sensor with a haloalkane functionality for protein labeling utilizing the bioorthogonal HaloTag-strategy (RhoCa-Halo, Scheme 2). First we derivatized 6 in a Sonogashira cross coupling reaction with Boc-protected propargylamine. After deprotection of the amine, the haloalkane functionality for protein localization was introduced by peptide bond formation. Finally, the methyl esters were converted to the free acids by saponification to obtain RhoCa-Halo.

Next, we evaluated the suitability of the newly synthesized RhoCa-Halo for protein labeling by an in vitro experiment. RhoCa-Halo was incubated with different concentrations of a purified HaloTag fused to green fluorescent protein (GFP-Halo) and the covalent attachment of the probe to the
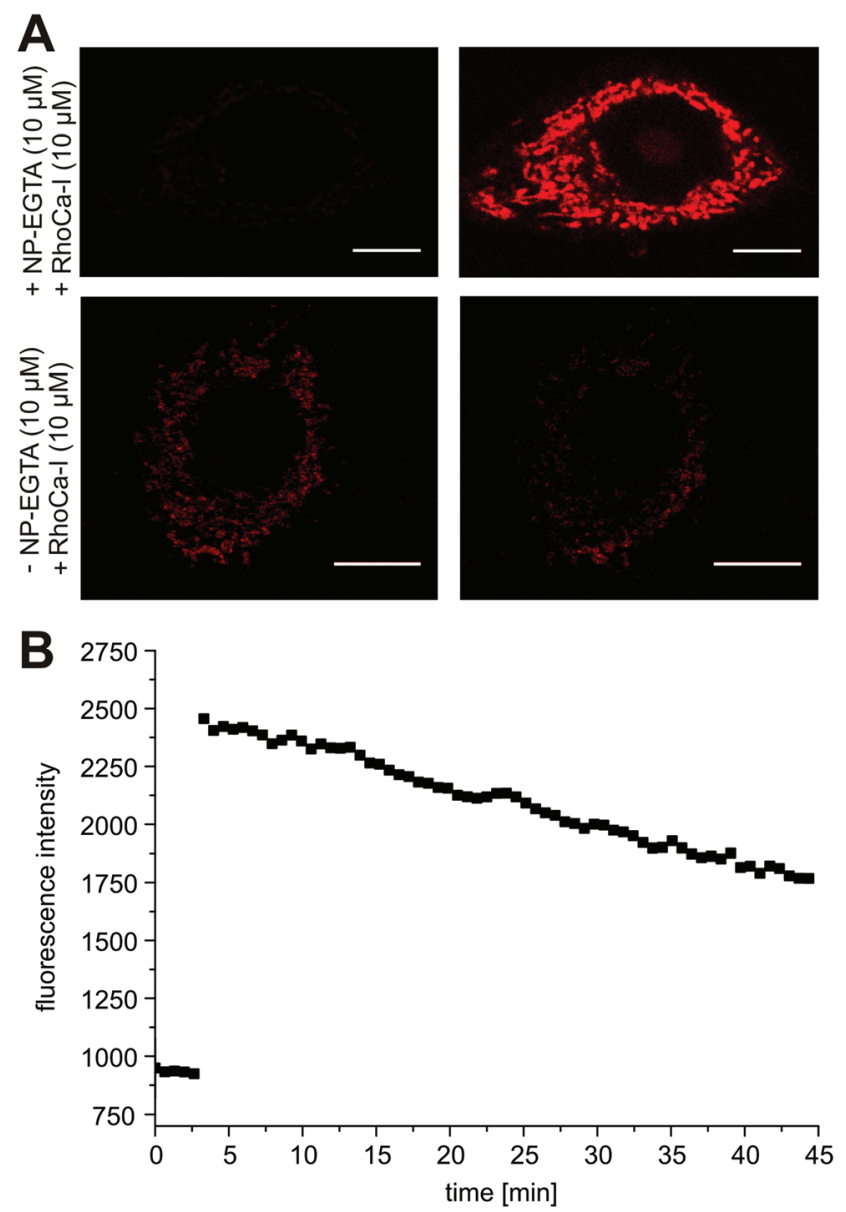

Fig. 2 (A) Live cell imaging of UV-mediated release of $\mathrm{Ca}^{2+}, \lambda_{\mathrm{ex}}=$ $559 \mathrm{~nm}$, detection at 572-672 nm. Upper panel: HeLa cells were incubated with $10 \mu \mathrm{M}$ NP-EGTA AM and endogenous release of calcium ions from cellular stores was stimulated by ATP. After incubation with $10 \mu \mathrm{M}$ RhoCa-I AM (upper panel, left), NP-EGTA-chelated $\mathrm{Ca}^{2+}$ was liberated by UV-radiation $(405 \mathrm{~nm}$ ) leading to a 2.5 -fold increase of fluorescence (upper panel, right). Lower panel: Cells were incubated with RhoCa-I AM and the sensor shows clear sub-cellular localization (lower panel, left). NP-EGTA AM was omitted in the experiment and no fluorescence increase is monitored upon UV-radiation (lower panel, right). Scale bars represent $10 \mu \mathrm{m}$. (B) Corresponding fluorescence intensity trace. UVmediated uncaging was conducted after $2 \mathrm{~min}$ with a short laser pulse.

model protein GFP-Halo was visualized by SDS-PAGE. Fig. 3 shows both the in-gel fluorescence scan of the SDS-gel and the Coomassie stain. From the fluorescence-scan it becomes clear, that GFP-Halo gets efficiently labeled with RhoCa-Halo. BSA served as negative control and did not show any labeling by the calcium sensor. As expected, the positive control with a non-calcium sensitive Halo-rhodamine, a commercially available substrate for the HaloTag (see ESI $\dagger$ for structure) resulted in labeling of the Halo fusion protein. When fluorescence emission was recorded at $\lambda_{\mathrm{em}}=580 \mathrm{~nm}$, we still detected fluorescence from GFP. Therefore, we chose to measure the fluorescence at $\lambda_{\mathrm{em}}=670 \mathrm{~nm}$, a range where GFP does not emit fluorescence light when excited, to selectively record fluorescence from RhoCa-Halo. Fig. 3 shows no fluorescence for 
<smiles>[R]CC#Cc1ccc(N(CC(=O)OC)CC(=O)OC)c(OCCOc2cc(-c3c4ccc(=[N+](C)C)cc-4oc4cc(N(C)C)ccc34)ccc2N(CC(=O)OC)CC(=O)OC)c1</smiles><smiles>C=CCOC(C)=O</smiles>

Scheme 2 Synthesis of RhoCa-Halo from 6 in a four-step procedure. Reaction conditions: (a) Pd(PPh $)_{4}, \mathrm{NEt}_{3}, \mathrm{Cul}$, tert-butyl prop-2-yn-1-ylcarbamate, DMF, rt, 70\%; (b) $4 \mathrm{M} \mathrm{HCl} /$ dioxane, rt, quant.; (c) $\mathrm{HO}_{2} \mathrm{CCH}_{2}$-[PEG-Halo], PyBOP, (iPr) $2 \mathrm{NEt}$, DMF, rt, quant.; (d) MeOH/DCM, $1 \mathrm{M} \mathrm{NaOH,} \mathrm{rt,} \mathrm{60 \% ;}$ (e) bromomethyl acetate, (iPr) ${ }_{2} \mathrm{NEt}, \mathrm{DCM}, \mathrm{rt}, 35 \%$.

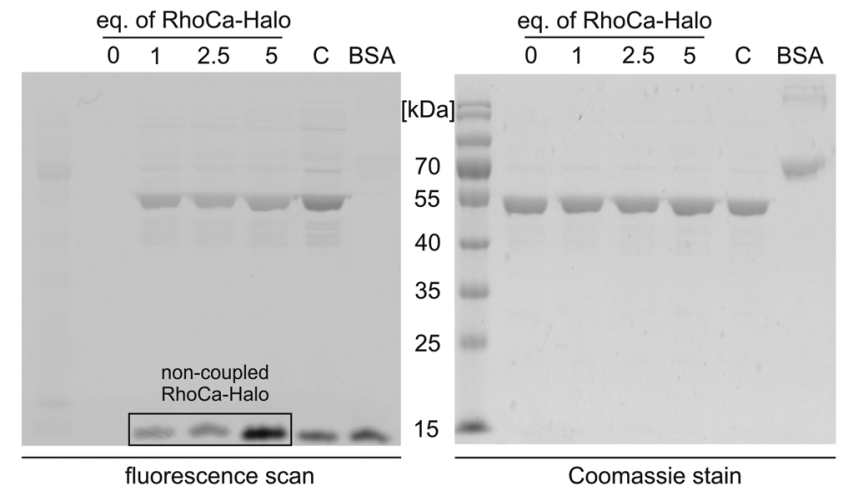

Fig. 3 GFP-Halo $(10 \mu \mathrm{M})$ was incubated with RhoCa-Halo $(0,10,25$ and $50 \mu \mathrm{M})$ and the successful labeling was verified by in-gel fluorescence (left). BSA (negative control) did not show any labeling when incubated with the calcium indicator. The commercially available noncalcium sensitive Halo-rhodamine (C) served as a positive control for site-specific labeling of the Halo fusion protein. (Settings for in gel fluorescence scan: $\lambda_{\mathrm{ex}}=532 \mathrm{~nm}$ and $\lambda_{\mathrm{em}}=670 \mathrm{~nm}$.)

the sample containing only GFP-Halo (c (RhoCa-Halo $=0 \mu \mathrm{M})$ ), which shows that the detected fluorescence only accounts for RhoCa-Halo. The detected fluorescence of the calcium sensor is due to calcium traces in the SDS running buffer and the increased calcium affinity at higher $\mathrm{pH}-$ values $^{26}(\mathrm{pH}=8.8$ in the resolving gel).

To determine the spectral properties of the calcium sensor, covalently attached to a protein, we incubated GFP-Halo with 5 -fold excess of RhoCa-Halo for two hours and subsequently removed the excess of RhoCa-Halo by spin-filtration. The labeled protein was then used for titration with calcium to determine the increase of fluorescence upon calcium binding. An average fluorescence turn-on upon calcium binding of 76 -fold with a quantum yield of $14.0 \pm 1.6 \%$ at $\left[\mathrm{Ca}^{2+}\right]_{\text {free }}=$ $39 \mu \mathrm{M}$ and $0.16 \pm 0.01 \%$ at $\left[\mathrm{Ca}^{2+}\right]_{\text {free }}=0 \mu \mathrm{M}$ was determined (Fig. S2A, $\uparrow \lambda_{\mathrm{ex}}=552 \mathrm{~nm}$ ). In a separate experiment we determined a 240 -fold fluorescence enhancement upon calcium binding for the free RhoCa-Halo (not bound to the protein). The observed lower fluorescence enhancement for the protein bound sensor might be caused by interactions between the calcium sensor and protein. As it is well known that the environment of a fluorophore has strong impact on its photophysical properties. The $K_{\mathrm{d}}$-value of the protein bound sensor was found to be $1.51 \pm 0.13 \mu \mathrm{M}$ (Fig. S2B $\dagger$ ) which makes it well suitable for investigations of calcium oscillations $\left(\left[\mathrm{Ca}^{2+}\right]_{\mathrm{i}}\right.$ up to $1 \mu \mathrm{M})^{27}$ and calcium sparks $\left(\left[\mathrm{Ca}^{2+}\right]_{\mathrm{i}}\right.$ up to $\left.10 \mu \mathrm{M}\right)$ in biological systems. ${ }^{28}$ After having established a method for the site specific labeling of the model protein GFP-Halo with the calcium-sensitive probe RhoCa-Halo, the newly developed calcium sensor found application in live cell experiments. Therefore, NIH/3T3 and HeLa cells were transiently transfected with H2B-GFP and Halo-H2B and incubated with the according AM-Ester (RhoCa-Halo AM). Epifluorescent microscopy indicated successful labeling of the nucleus with the localizable calcium sensor in both cell lines (Fig. 4).

Next, we investigated the behavior of the calcium sensor in live cells after stimulation with ATP, inducing cytosolic influx of calcium ions from endogenous stores. Therefore, HeLa cells were transfected with Halo-H2B and incubated with 


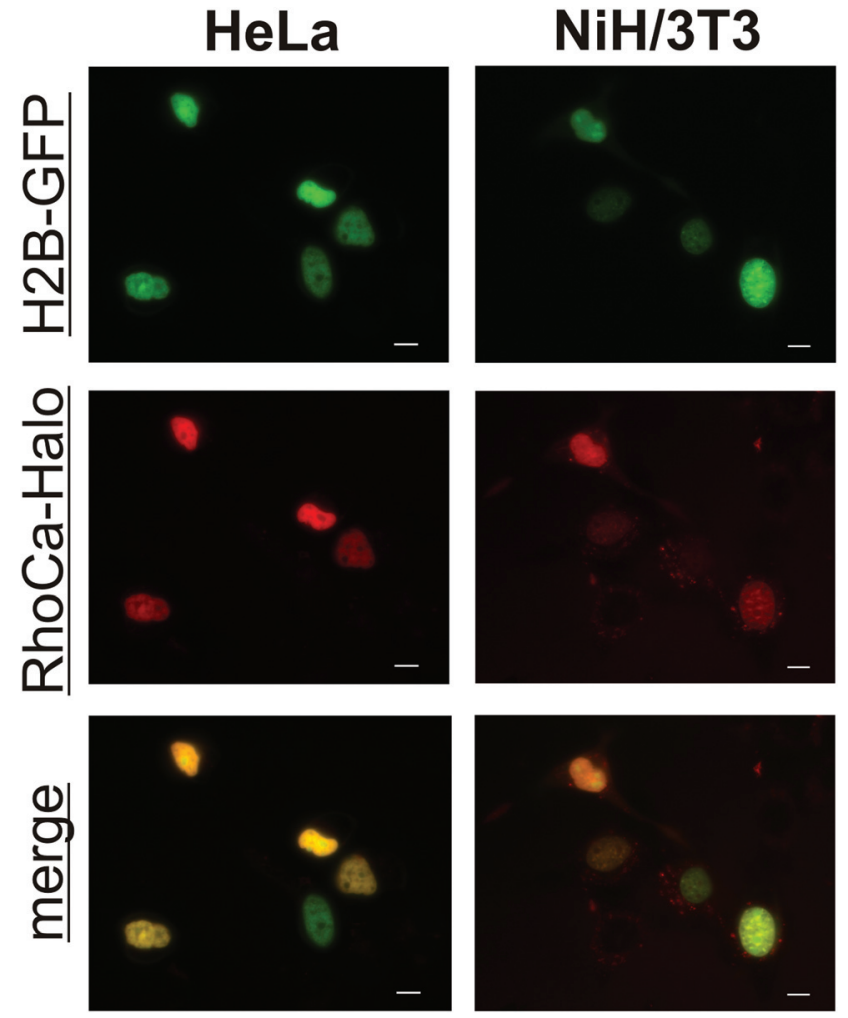

Fig. 4 Epifluorescence microscopic images of H2B-GFP and Halo-H2B co-transfected HeLa and $\mathrm{NIH} / 3 \mathrm{~T} 3$ cells after incubation with $1 \mu \mathrm{M}$ RhoCa-Halo AM. The overlay of the red and the green channel indicates successful labeling of the nucleus in living cells. Scale bars represent $10 \mu \mathrm{m}$. GFP was excited at $472 \pm 20 \mathrm{~nm}$ (green channel, GFP) and the RhoCa-Halo was excited at $562 \pm 20 \mathrm{~nm}$ (red channel, RhoCa-Halo).

RhoCa-Halo AM. Non-transfected cells were distinguished from the transfected cells by confocal microscopy. Cytosolic influx of free calcium ions was then stimulated with $100 \mu \mathrm{M}$ ATP and a noticeable increase of fluorescence was observed in the nucleus of the transfected and labeled cells directly upon addition of ATP (Fig. 5). The non-transfected cells did not show any detectable increase of fluorescence in the nucleus. This clearly demonstrated the potential of the fluorescent sensor RhoCa-Halo as a localizable calcium sensor to monitor spatiotemporal changes of free calcium ions in live cell experiments.

\section{Conclusion}

In conclusion, we developed a new localizable rhodamine based calcium sensor which can be applied in live cell imaging. RhoCa-Halo is a localizable highly sensitive calcium sensor which exhibits an increase of fluorescence upon calcium-binding, thereby enabling monitoring spatiotemporal changes of calcium concentrations in living cells. We demonstrated its application in in vitro and live cell experiments. Moreover, RhoCa-I serves as a general building block that can be readily derivatized by Sonogashira cross-coupling to intro-

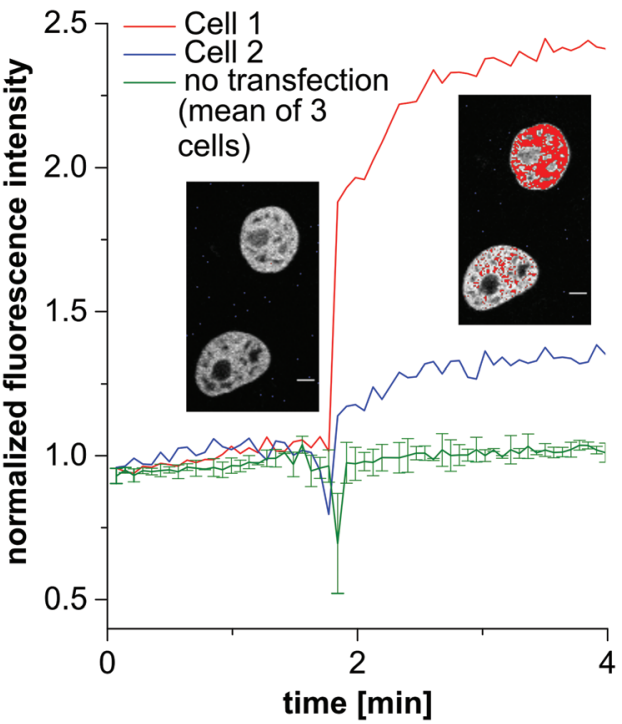

Fig. 5 Confocal microscopic images of Halo-H2B transfected HeLa cells after incubation with $1 \mu \mathrm{M}$ RhoCa-Halo AM, $\lambda_{\mathrm{ex}}=559 \mathrm{~nm}$, detection at $572-672 \mathrm{~nm}$. Cytosolic influx of free calcium ions was stimulated by addition of ATP. A significant increase of fluorescence intensity in the nucleus was detected immediately after addition of ATP. Shown are the normalized nuclear fluorescence intensity traces of the depicted HeLa cells (blue and red curve). The average normalized fluorescence intensity in the nucleus of three non-transfected cells is shown in green. Scale bars $5 \mu \mathrm{m}$.

duce alternative functionalities to the rhodamine calcium sensor. RhoCa-Halo is the first localizable small molecule based calcium sensor with excitation in the green spectrum and represents a valuable addition to the toolbox of calcium imaging. The sensor can be combined with other sensors which are spectrally separated. Furthermore, the application of the HaloTag labeling strategy allows multi-color calcium imaging of different organelles in living cells when combined with the orthogonal SNAP-tag based localizable calcium sensor, ${ }^{11}$ an Indo-1 derivative with excitation in the near-UV $\left(\mathrm{Ex}_{\max }=350 \mathrm{~nm} ; \mathrm{Em}_{\max }=475 \mathrm{~nm}\right)$. The specific localization of a fluorescent calcium sensor to any POI has great potential to study the spatiotemporal regulation of calcium as a second messenger. Furthermore we would like to point out that the high photo-stability and specific photo-physical properties of the rhodamine moiety makes the newly developed RhoCa-Halo probe a potential candidate for application in super-resolution microscopy. ${ }^{29}$

\section{Acknowledgements}

This work was supported by the Deutsche ForschungsGemeinschaft DFG (SPP1623, WO 1888/1-2). We thank the Nikon Imaging Center Heidelberg for access to fluorescence microscopes. We gratefully acknowledge Carsten Schultz (EMBL) for access to confocal microscopes and for providing NP-EGTA AM. We thank the Department of Infectious Diseases 
(Medical Biology and Hygiene, group of Konrad Bode) for access to the in-gel fluorescence scanner. We acknowledge the support from the Inorganic Chemical Institute of the University of Heidelberg (Prof. Dr Markus Enders and Beate Termin) for providing access to the NMR facility for spectroscopic measurements. We thank Mathis Baalmann, Achim Wieczorek and Michael Heimes for scientific support and Heiko Rudy for technical support.

\section{Notes and references}

1 D. E. Clapham, Cell, 2007, 131, 1047-1058.

2 (a) J. Zhang, R. E. Campbell, A. Y. Ting and R. Y. Tsien, Nat. Rev. Mol. Cell Biol., 2002, 3, 906-918; (b) M. Mank and O. Griesbeck, Chem. Rev., 2008, 108, 1550-1564; (c) T. Rose, P. M. Goltstein, R. Portugues and O. Griesbeck, Front. Mol. Neurosci., 2014, 7, 88.

3 A. Miyawaki, J. Llopis, R. Heim, J. M. McCaffery, J. A. Adams, M. Ikura and R. Y. Tsien, Nature, 1997, 388, 882-887.

4 O. Griesbeck, G. S. Baird, R. E. Campbell, D. A. Zacharias and R. Y. Tsien, J. Biol. Chem., 2001, 276, 29188-29194.

5 O. Tour, S. R. Adams, R. A. Kerr, R. M. Meijer, T. J. Sejnowski, R. W. Tsien and R. Y. Tsien, Nat. Chem. Biol., 2007, 3, 423-431.

6 M. Oheim, M. van 't Hoff, A. Feltz, A. Zamaleeva, J. M. Mallet and M. Collot, Biochim. Biophys. Acta, 2014, 1843, 2284-2306.

7 G. Grynkiewicz, M. Poenie and R. Y. Tsien, J. Biol. Chem., 1985, 260, 3440-3450.

8 A. Minta, J. P. Kao and R. Y. Tsien, J. Biol. Chem., 1989, 264, 8171-8178.

9 K. R. Gee, K. A. Brown, W. N. Chen, J. Bishop-Stewart, D. Gray and I. Johnson, Cell Calcium, 2000, 27, 97-106.

10 R. M. Paredes, J. C. Etzler, L. T. Watts, W. Zheng and J. D. Lechleiter, Methods, 2008, 46, 143-151.

11 (a) M. Bannwarth, I. R. Correa, M. Sztretye, S. Pouvreau, C. Fellay, A. Aebischer, L. Royer, E. Rois and K. Johnsson, ACS Chem. Biol., 2009, 4, 179-190; (b) M. Kamiya and K. Johnsson, Anal. Chem., 2010, 82, 6472-6479.

12 B. Raju, E. Murphy, L. A. Levy, R. D. Hall and R. E. London, Am. J. Physiol., 1989, 256, C540-C548.

13 I. J. Arroyo, R. R. Hu, G. Merino, B. Z. Tang and E. PenaCabrera, J. Org. Chem., 2009, 74, 5719-5722.
14 R. Y. Tsien, Biochemistry, 1980, 19, 2396-2404.

15 G. V. Los, L. P. Encell, M. G. McDougall, D. D. Hartzell, N. Karassina, C. Zimprich, M. G. Wood, R. Learish, R. F. Ohana, M. Urh, D. Simpson, J. Mendez, K. Zimmerman, P. Otto, G. Vidugiris, J. Zhu, A. Darzins, D. H. Klaubert, R. F. Bulleit and K. V. Wood, ACS Chem. Biol., 2008, 3, 373-382.

16 (a) C. Eggeling, J. Widengren, R. Rigler and C. A. M. Seidel, Anal. Chem., 1998, 70, 2651-2659; (b) B. Hein, K. I. Willig, C. A. Wurm, V. Westphal, S. Jakobs and S. W. Hell, Biophys. J., 2010, 98, 158-163.

17 J. Qiu, Y. W. Tan, A. M. Hagenston, M. A. Martel, N. Kneisel, P. A. Skehel, D. J. A. Wyllie, H. Bading and G. E. Hardingham, Nat. Commun., 2013, 4.

18 (a) G. Hajnoczky, L. D. Robbgaspers, M. B. Seitz and A. P. Thomas, Cell, 1995, 82, 415-424; (b) D. R. Trollinger, W. E. Cascio and J. J. Lemasters, Biochem. Biophys. Res. Commun., 1997, 236, 738-742.

19 B. Agnew, J. Beechem, K. Gee, R. Haugland, T. Steinberg and W. Patton, PCT/US 2004/036968, 2004.

20 J. N. Demas and G. A. Crosby, J. Phys. Chem., 1971, 75, 9911024.

21 R. F. Kubin and A. N. Fletcher, J. Lumin., 1982, 27, 455462.

22 R. Pethig, M. Kuhn, R. Payne, E. Adler, T. H. Chen and L. F. Jaffe, Cell Calcium, 1989, 10, 491-498.

23 G. C. Ellis-Davies, Nat. Methods, 2007, 4, 619-628.

24 (a) A. Luckhoff and R. Busse, J. Cell. Physiol., 1986, 126, 414-420; (b) F. A. Gonzalez, E. Rozengurt and L. A. Heppel, Proc. Natl. Acad. Sci. U. S. A., 1989, 86, 4530-4534; (c) R. Charest, P. F. Blackmore and J. H. Exton, J. Biol. Chem., 1985, 260, 5789-5794.

25 D. G. Lambert, Calcium signaling protocols, Springer Science \& Business Media, 2006.

26 U. Quast, A. M. Labhardt and V. M. Doyle, Biochem. Biophys. Res. Commun., 1984, 123, 604-611.

27 A. T. Harootunian, J. P. Kao, S. Paranjape and R. Y. Tsien, Science, 1991, 251, 75-78.

28 M. B. Cannell and C. Soeller, J. Gen. Physiol., 1999, 113, 373-376.

29 (a) G. T. Dempsey, J. C. Vaughan, K. H. Chen, M. Bates and X. Zhuang, Nat. Methods, 2011, 8, 1027-1036; (b) M. Heilemann, S. van de Linde, M. Schuttpelz, R. Kasper, B. Seefeldt, A. Mukherjee, P. Tinnefeld and M. Sauer, Angew. Chem., Int. Ed., 2008, 47, 6172-6176. 